Network Working Group

Request for Comments: 3827

Category: Informational

K. Sarcar

Sun Microsystems, Inc.

June 2004

\title{
Additional Snoop Datalink Types
}

Status of this Memo

This memo provides information for the Internet community. It does not specify an Internet standard of any kind. Distribution of this memo is unlimited.

Copyright Notice

Copyright (C) The Internet Society (2004).

Abstract

The snoop file format provides a way to store and exchange datalink layer packet traces. This document describes extensions to this file format to support new media.

\section{Introduction}

[RFC1761] defines the snoop file format used to store captured network packets for tools that capture, display, and interpret network traffic. The file format specifies a header containing the Datalink Type field that identifies the network's datalink type. This document defines new values for this field, as well as an IANA registry for future datalink types.

2. New Datalink Types

In addition to the Datalink Type codes listed in [RFC1761], this document defines the following type codes for the corresponding media:

$\begin{array}{ll}\text { Datalink Type } & \text { Code } \\ -------- & --- \\ & \\ \text { Fibre Channel } & 16 \\ \text { ATM } & 17 \\ \text { ATM Classical IP } & 18 \\ \text { IP over Infiniband } & 26\end{array}$

The IP over Infiniband packet format is described in [IPoIB]. 


\section{IANA Considerations}

This document created a new IANA registry named "Snoop Datalink Types" to hold the various possible 32-bit (4 octet) snoop datalink types. This new registry holds the values previously defined in [RFC1761] and tabulated below:

$\begin{array}{ll}\text { Datalink Type } & \text { Code } \\ \text { IEEE 802.3 } & --- \\ \text { IEEE 802.4 Token Bus } & 1 \\ \text { IEEE 802.5 Token Ring } & 2 \\ \text { IEEE 802.6 Metro Net } & 3 \\ \text { Ethernet } & 4 \\ \text { HDLC } & 5 \\ \text { Character Synchronous } & 6 \\ \text { IBM Channel-to-Channel } & 7 \\ \text { FDDI } & 8 \\ \text { Other } & 9\end{array}$

Additionally, the new registry also holds the values defined above in section 2 of this document.

All new allocations and assignments to this registry starting from code 27 will follow the First Come First Served policy outlined in [BCP0026]. Type codes up to 26 not defined by this section of the document (10-15 and 19-25) are considered reserved.

4. Security Considerations

The addition of new datalink type codes to the existing file format poses no known security risks.

5. Acknowledgements

The author would like to thank Jim Carlson, Brent Callaghan, and Bill Strahm for meticulously reviewing this document.

6. References

6.1. Normative References

[RFC1761] Callaghan, B. and R. Gilligan, "Snoop Version 2 Packet Capture File Format", RFC 1761, February 1995. 
[BCP0026] Narten, T. and H. Alvestrand, "Guidelines for Writing an IANA Considerations Section in RFCs", BCP 26, RFC 2434, October 1998.

\subsection{Informative References}

[IPoIB] Kashyap, V. and H.K. Chu, "IP encapsulation and address resolution over InfiniBand networks", Work in Progress, April 2003.

7. Author's Address

Kanoj Sarcar

Sun Microsystems, Inc.

14 Network Circle

Bldg 14, MPK14-333

Menlo Park, CA 94025

Phone: 1-650-786-4785

EMail: kanoj.sarcarasun.com 
8. Full Copyright statement

Copyright (C) The Internet society (2004). This document is subject to the rights, licenses and restrictions contained in BCP 78, and except as set forth therein, the authors retain all their rights.

This document and the information contained herein are provided on an "AS IS" basis and THE CONTRIBUTOR, THE ORGANIZATION HE/SHE REPRESENTS OR IS SPONSORED BY (IF ANY), THE INTERNET SOCIETY AND THE INTERNET ENGINEERING TASK FORCE DISCLAIM ALL WARRANTIES, EXPRESS OR IMPLIED, INCLUDING BUT NOT LIMITED TO ANY WARRANTY THAT THE USE OF THE INFORMATION HEREIN WILL NOT INERINGE ANY RIGHTS OR ANY IMPLIED WARRANTIES OF MERCHANTABILITY OR FITNESS FOR A PARTICULAR PURPOSE.

Intellectual Property

The IETF takes no position regarding the validity or scope of any Intellectual Property Rights or other rights that might be claimed to pertain to the implementation or use of the technology described in this document or the extent to which any license under such rights might or might not be available; nor does it represent that it has made any independent effort to identify any such rights. Information on the procedures with respect to rights in RFC documents can be found in BCP 78 and BCP 79 .

Copies of IPR disclosures made to the IETF Secretariat and any assurances of licenses to be made available, or the result of an attempt made to obtain a general license or permission for the use of such proprietary rights by implementers or users of this specification can be obtained from the IETF on-line IPR repository at http://www.ietf.org/ipr.

The IETF invites any interested party to bring to its attention any copyrights, patents or patent applications, or other proprietary rights that may cover technology that may be required to implement this standard. Please address the information to the IETF at ietfipraietf.org.

Acknowledgement

Funding for the RFC Editor function is currently provided by the Internet Society. 